\title{
AVALIAÇÃO DO IMPACTO ECONÔMICO DA MASTITE EM REBANHOS BOVINOS LEITEIROS
}

\section{M.A. Lopes*, F.A. Demeu**, C.M.B.M. da Rocha, G.M. da Costa, A. Franco Neto, G. dos Santos**}

Universidade Federal de Lavras, Departamento de Medicina Veterinária, CP 3037, CEP 37200-000, Lavras, MG, Brasil. E-mail: malopes@dmv.ufla.br

\begin{abstract}
RESUMO
Os objetivos desta pesquisa foram simular, analisar e quantificar o impacto econômico da frequência média anual de mastite clínica em rebanhos bovinos leiteiros. A pesquisa foi realizada por meio de simulação no sistema computacional CU\$TO MASTITE, considerando rebanhos leiteiros com 1, 7 e 15\% de mastite clínica. Foram consideradas como prevenção as despesas com monitoramento (cultura e antibiograma, contagem de células somáticas no tanque e contagem de células somática individual), pré e pós dipping, vacinação, tratamento de vacas secas e manutenção de ordenhadeira. Como medida curativa considerou-se apenas tratamento de casos clínicos. $\mathrm{O}$ impacto da mastite foi estimado como sendo o total em perdas acrescido das despesas com prevenção e tratamento de casos clínicos. $\mathrm{O}$ aumento da frequência média anual de mastite influenciou diretamente no impacto econômico da mastite, evidenciando a necessidade de monitoramento da mastite clínica e subclínica e adoção de medidas preventivas para diminuir os prejuízos ocasionados por essa enfermidade. As despesas com tratamento preventivo representaram, no máximo, 19,7\% do impacto econômico, o que demonstra vantagens em investir nessa prática, pois ela irá contribuir significativamente para reduzir o impacto econômico da mastite.
\end{abstract}

PALAVRAS-CHAVE: Bovinocultura leiteira, mastite clínica, sanidade animal.

\begin{abstract}
INFLUENCEOF THE ECONOMIC IMPACTOF MASTITISIN DAIRY CATTLE. The objectives of this research were to analyze and quantify the economic impact of the annual average frequency of clinical mastitis in dairy cattle. The research was carried through data simulation in the CU\$TO MASTITE computational system, considering dairy cattle with 1,7 and $15 \%$ of clinical mastitis. The expenditures considered as prevention included those of monitoring (culture and antibiogram, bulk tank somatic cell count and individual somatic cell count) pre- and post-dipping, vaccination, treatment of dry cows and maintenance of the milking machine. The measures considered as healing consisted only of the treatment of clinical cases. The impact of the mastitis was estimated as being the total in losses in addition to the expenditures with prevention and treatment of clinical cases. The increase of the annual average frequency of mastitis directly influenced the economic impact of the mastitis. The higher economic impact evidences the need for the monitoring of clinical and subclinical mastitis and the adoption of preventative measures to diminish the damages caused by this disease. The expenditures with preventive treatment represented, at maximum, $19.7 \%$ of the economic impact, which demonstrates the advantages of investing in this practice, since it contributes significantly toward reducing the economic impact of mastitis.
\end{abstract}

KEY WORDS: Animal health, clinical mastitis, dairy cattle.

\section{INTRODUÇÃO}

A mastite caracteriza-se por uma inflamação da glândula mamária, geralmente de caráter infeccioso, podendo ser classificada como clínica ou subclínica. A mastite clínica apresenta sinais evidentes, tais como: edema de úbere, aumento de temperatura, endurecimento, dor na glândula mamária, grumos, pus e quaisquer outras alterações das características do leite(FONSECA; SANTOS, 2000). Na forma subclínica não

*Bolsista do CNPq.

**Pós-graduando em Ciências Veterinárias - Bolsista da CAPES. 
são observadas alterações macroscópicas e, sim, alterações na composição e volume do leite produzido; portanto, não apresenta sinais visíveis de inflamação do úbere (CulLor, 1993). Essa característica favorece sua disseminação no rebanho e ainda proporciona ao produtor uma falsa tranquilidade, em relação à ocorrência de mastite. No entanto, estima-se que para cada caso clínico da enfermidade ocorram 35 de subclínicos (FonseCA; SANTOS, 2000).

De acordo com ViannI; LÁzARO (2003), os casos clínicos, devido a gravidade com que acometem os animais, são de fundamental importância, pois podem levar a altos prejuízos como: descarte precoce de animais, gastos com medicamentos, redução na produção, descarte deleite, além de poder levar o animal a morte. O leite proveniente de vacas infectadas apresenta modificação em sua composição química, alterando consequentemente suas características organolépticas, físicas, químicas e microbiológicas.

SANTOS; FonSECA (2007) recomendam como meta para saúde da glândula mamária, que a incidência de mastite clínica seja menor que $1 \%$ ao mês. Dados experimentais relacionados ao tema têm apresentado muitas variações em relação à ocorrência de frequência de casos clínicos em rebanhos bovinos.

Devidoà grande importância da mastite, diversos pesquisadores têm estudado diferentes aspectos, tais como: incidência de casos clínicos; contagem de células somáticas e redução da produção; descarte de vacas em virtude de mastite; prevalência, incidência e frequência de casos clínicos; influência das células somáticas na qualidade do leite. No entanto, poucas pesquisas avaliam o impacto econômico da mastite sob as condições de exploração predominantes no Brasil. Nas literaturas que abordam o assunto (BAR et al., 2008), não há detalhamento em relação aos indicadores técnicos e gerenciais adotados. Em vista dos aspectos apresentados, bem como a importância do tema, realizou-se esta pesquisa cujos objetivos foram simular, analisar e quantificar o impacto econômico da mastite clínica em rebanhos bovinos leiteiros considerando diferentes taxas deincidência.

\section{MATERIAL E MÉTODOS}

A pesquisa foiconduzida por meio de simulaçãode dados, utilizando o sistema computacional "CU\$TO MASTITE" (LOPEs et al., 2007). Os fatores utilizados, e os seus respectivos valores, foram: quantidade de vacas em lactação (100); percentual de vacas secas (33); produção média diária de leite por animal (20 $\mathrm{kg}$ ); número de ordenha diária (2); intervalo de partos
(15 meses); contagem de células somáticas do tanque (500.000 células somáticas $/ \mathrm{mL}$ ); quartos acometidos clinicamente (1); quantidade de doses de vacina para vaca seca (3); percentual de descarte devido à mastite (4\%); percentual anual de morte em virtude da mastite (1\%); valor de aquisição de uma vaca $(\mathrm{R} \$ 3.000,00)$ e valor de descarte da vaca $(\mathrm{R} \$ 1.314,00)$. Para verificar a influência da frequência de casos clínicos no impacto econômico da mastite, optou-se por valores de: $1 \%$, por ser esse considerado um indicativo de boa saúde da glândula mamária (SANTOS; FONSECA, 2007); 7\%, encontrado por BuENO et al. (2002); e 15\% encontrados por Costa et al. (2001), ao trabalharem com 19.388 animais, de 257 rebanhos de Minas Gerais e São Paulo, no período de 1993 a 1997.

As despesas com tratamento curativo envolveram aquelas com casos clínicos subagudos e agudos, que neste estudo considerou os valores de $75 \%$ e $25 \%$, respectivamente. Foram computadas as despesas com o tratamento de mastite clínica subaguda, por meio da soma dos preços dos antibióticos locais aplicados (três dias) e mão-de-obra utilizada para realizar essa atividade (10 minutos por teto acometido). $\mathrm{O}$ valor estimado para caso agudo resultou da soma dos gastos para tratamento local e sistêmico por um período de cinco dias. Foram considerados os valores de mão-de-obra, seringa e agulha, para realização do tratamento sistêmico. A quantidade total de casos clínicos por mês foi obtida por meio da fórmula* proposta por SANTOS; FONSECA (2007).

O valor obtido foi multiplicado pela quantidade de meses do ano, estimando, assim, a quantidade de casos clínicos por ano.

O custo operacional efetivo anual de tratamento da mastite clinica, por vaca em lactação, foi obtido pelo somatório docusto anual de tratamento de casos clínicos subagudos e do custo anual de tratamento de casos clínicos agudos dividido pelo número de vacas em lactação.

$\mathrm{O}$ valor pago pelo $\mathrm{kg}$ de leite comercializado foi de $\mathrm{R} \$ 0,67$, obtido na Cooperativa Agrícola Alto Rio Grande, no Município de Lavras, no mês de novembro de 2008. O valor considerado para a conversão do dólar foi US\$ 1.00 igual a R 2 2,25. Foi considerado como custo de prevenção as despesas com monitoramento [cultura e antibiograma, contagem de células somáticas no tanque (CCST) e contagem de células somáticas individuais (CCSI)], pré e pós dipping, vacinação e tratamento de vacas secas. Como medidas curativas, levou-se em conta apenas as despesas com tratamentos de casos clínicos, cuja percentagem considerada foi de 1\%, 7\% e 15\% das vacas em lactação.

\footnotetext{
*\% de mastiteclínica do mês $=\frac{(\text { dias de mastite clínica } / \text { dias do mês }) \times 100}{n^{n} \text { o médio de vacas em lactação }}$
} 
O impacto da mastite (IM) foi estimado como sendo:

$\mathrm{IM}=$ Total em perdas + tratamento preventivo + tratamento curativo, onde:

Total de perdas $=$ perdas em leite (redução na produção e descarte de leite durante o tratamento e período de carência do antibiótico);

Tratamento preventivo $=$ despesas com antibiograma e cultura + CCST + CMT + pré-dipping + pós-dipping + tratamento de vacas secas + vacinação de vacas secas;

Tratamento curativo $=$ despesas com aplicação do antibiótico local + antibiótico sistêmico.

As perdas deleiteforam quantificadas utilizando uma regressão linear conforme preconizado pelo NMC (NICKERSON et al., 1996):

$\mathrm{Y}=-4,7908+0,0226 \mathrm{x}$

Onde " $y$ " é a porcentagem de perda de leite e " $x$ " a contagem de células somáticas.

\section{RESULTADOS E DISCUSSÃO}

O impacto econômico anual da mastite foi de R\$ $72.784,74 ; \mathrm{R} \$ 160.481,82$; e $\mathrm{R} \$ 277.411,25$, para frequências médias anuais de 1,7 e $15 \%$, respectivamente. Tomando-se por referência uma vaca em lactação, variou de $\mathrm{R} \$ 727,85$ a $\mathrm{R} \$ 2.774,11$ e de $\mathrm{R} \$ 0,1090$ a $\mathrm{R} \$$
0,5985/ kg deleite, para frequências médias anuais de 1 e $15 \%$ de mastite clínica, respectivamente (Tabela 1). As diferenças são resultantes do maior volume de leite descartado, em decorrência dos tratamentos curativos e pelo aumento da quantidade de casos clínicos tratados, que aumentaram os gastos com mão-de-obra e medicamentos, o que resultou em aumento do impacto econômico. A redução da produção também contribuiu para impactar estes resultados.

No que diz respeito aos casos clínicos, as quantidades foram de 161,1.127 e 2.415 para as frequências médias anuais de 1,7e15\%, respectivamente. Desses, 129; 902 e 1.932 (75\%) foram casos subagudos; e 32; 225 e 483 , casos agudos (25\%), para as frequências médias anuais estudadas.

O custo do tratamento curativo por vaca em lactação/ano foi estimado em R \$ 48,34 (US\$ 21,48); R \$ 338,39 (US\$150,40) e R $\$ 725,13$ (US\$322,28), para 1, 7 e $15 \%$ de frequência média anual de casos clínicos, respectivamente. Esses valores resultaram em custo operacional efetivo de tratamento curativo $/ \mathrm{kg}$ de leite produzido de $\mathrm{R} \$ 0,0072 ; \mathrm{R} \$ 0,0583$ e $\mathrm{R} \$ 0,1565$, sendo inferiores às medidas de prevenção somente quando a frequência média anual foi de $1 \%$. A diferença foi devido ao aumento do custo com tratamento curativo ocasionado por maior quantidade de casos clínicos. Para as frequências médias anuais de 1

Tabela 1 - Simulação do impacto econômico da mastite, por kg de leite, vaca em lactação e rebanho (vacas em lactação + vacas secas), em Reais, em função da frequência média anual de mastite clínica, em rebanhos de 100 vacas holandesas em lactação, com produção diária de $20 \mathrm{~kg}$.

\begin{tabular}{|c|c|c|c|}
\hline \multirow{3}{*}{ Especificação } & \multicolumn{3}{|c|}{ Frequência média anual de mastite clínica } \\
\hline & $1 \%$ & $7 \%$ & $15 \%$ \\
\hline & \multicolumn{3}{|c|}{$\mathrm{R} \$$} \\
\hline COE da prevenção/kg de leite produzido & 0,0215 & 0,0248 & 0,0310 \\
\hline $\mathrm{COE}$ do tratamento curativo/ $\mathrm{kg}$ de leite produzido & 0,0072 & 0,0583 & 0,1565 \\
\hline COE do tratamento preventivo + curativo $/ \mathrm{kg}$ de leite produzido & 0,0287 & 0,0831 & 0,1874 \\
\hline Perdas de produção/kg de leite produzido & 0,0802 & 0,1935 & 0,4111 \\
\hline Impacto econômico $/ \mathrm{kg}$ de leite & 0,1090 & 0,2766 & 0,5985 \\
\hline COE do tratamento curativo de caso subagudo/vaca afetada & 28,68 & 28,68 & 28,68 \\
\hline COE do tratamento curativo de caso agudo/vaca afetada & 110,43 & 110,43 & 110,43 \\
\hline COE da prevenção/vaca em lactação/ano & 143,63 & 143,63 & 143,63 \\
\hline COE da prevenção/rebanho (vacas lactação + vacas secas)/ano & 107,99 & 107,99 & 107,99 \\
\hline $\begin{array}{l}\text { COE do tratamento curativo (caso subagudo + agudo)/vaca em lacta- } \\
\text { ção/ano }\end{array}$ & 48,34 & 338,39 & 725,13 \\
\hline $\begin{array}{l}\text { COE do tratamento prev. + curativo (caso subagudo + agudo)/vaca em } \\
\text { lactação/ano }\end{array}$ & 191,97 & 482,02 & 868,75 \\
\hline Perdas de leite (redução na produção+ descarte)/vaca em lactação/ano & 535,88 & $1.122,80$ & $1.905,36$ \\
\hline Impacto econômico/vaca em lactação/ano & 727,85 & $1.604,82$ & $2.774,11$ \\
\hline${ }^{1}$ Impacto econômico total (perdas + despesas)/ano & $72.784,74$ & $160.481,82$ & $277.411,25$ \\
\hline \multicolumn{4}{|c|}{$\begin{array}{l}\text { COE = custo operacional efetivo; }{ }^{1} \text { Impacto econômico total: gastos com prevenção, tratamento curativo, perdas em } \\
\text { virtude da redução na produção dos animais acometidos por mastite e descarte de leite dos animais em tratamento. } \\
\text { Valores dos insumos e produtos utilizados foram obtidos no comércio local de Lavras, em novembro de } 2008 .\end{array}$} \\
\hline
\end{tabular}


subclínica e, ao final, foram observadas variações de 4 a $11 \%$. A mastite clínica também apresentou efeito direto, pois a taxa de 5,0 a $8,0 \%$ no início do estudo caiu para $2,5 \%$ no final das observações. Esses dados de eficiência dos programas de controle de mastite são reflexos da diminuição dos custos com gastos com casos clínicos (em especial), não exigindo tratamentos emergenciais e ônus com o descarte de leite, reposição e morte de animais.

O tratamento curativo de uma vaca com mastite apresentando sintomas clínicos da doença foi de R\$ 28,68 (US\$ 12,75) para cada caso subagudo e de R \$110,43 (US\$ 49,08), para casos agudos (Tabela 1). Tais valores estão abaixo dos encontrados por BAR et al. (2008) (US\$179,00) e acima dos encontrados por HoBlet etal. (1991)(US\$107,00) e também aos R \$24,55 encontrados por Costa et al. (2005), porém, esses últimos não mencionaram qual a prevalência de mastite clínica no rebanho, nem se os valores encontrados foram para casos subagudos ou agudos. Neste estudo, foram considerados tratamentos de casos agudos e subagudos, sendo computadas as despesas com o tratamento de mastite clínica subaguda, por meio da soma dos antibióticos locais aplicados (três dias) e mão-de-obra utilizada para realizar essa atividade (10 minutos por teto acometido, com valor unitário de $\mathrm{R} \$ 0,04)$. O valor estimado para caso agudo resultou da soma dos gastos para tratamento local e sistêmico por um período de cinco dias. Foram considerados os valores de mão-de-obra, seringa e agulha, para realização do tratamento sistêmico.

Os custos operacionais efetivos da prevenção/ kg de leite produzido foram de $\mathrm{R} \$ 0,0215 ; \mathrm{R} \$ 0,0248$ e R\$ 0,0310, para frequências médias anuais de 1, 7 e $15 \%$, respectivamente. A diferença encontrada foi em decorrência da menor quantidade de leite comercializada, ocasionada pelo aumento do descarte de leite de animais em tratamento. Tomando por referência uma vaca em lactação, esse foi estimado em R $\$ 143,63$ (US\$ 63,84). O COE da prevenção por vaca em lactação encontrado neste estudo foi superior a estimativa de MILLER et al. (1993), de US\$14,50 por vaca/ano. Ovalor encontrado neste trabalho foi para vacas em lactação; já os pesquisadores citados não mencionam se foram consideradas vacas do rebanho ou vacas em lactação.

A prevenção é um item que deve receber grande atenção por parte dos técnicos e pecuaristas. Como podeser observado na Tabela 2, esse só não foi inferior às perdas com morte e desvalorização de matrizes, em todas as frequências médias anuais estudadas; e ao tratamento curativo e descarte de leite de animais em tratamento, quando a frequência média anual foi de $1 \%$. Tais valores evidenciam a importância de se investir e de se adotar medidas preventivas, que incluam não somente os tratamentos preventivos, como também medidas de manejo, principalmente na ordenha, bem como boas condições de higiene nas instalações, visando diminuir novas infecções. Lopes et al. (2004) verificaram que cuidados com a obtenção higiênica do leite têm sido negligenciados por parcela significativa de produtores deleite, pois, ao fazerem o levantamento de todas as despesas operacionais efetivas em 16 propriedades leiteiras do sul de Minas Gerais, constataram que em 50\% não houve nenhuma despesa com aquisição de soluções prée pós dipping, detergentes ácidos ealcalinos, papel toalha, desinfetantes de demais produtos utilizados na ordenha.

Quanto ao item que provocou maior impacto, há diferenças em função da frequência média anual de mastite clínica (Tabela 2). Para 1\%, o maior foi provocado pela redução na produção de leite ( $\mathrm{R} \$$ $31.836,50)$, representando $43,8 \%$ do impacto ocasionado pela mastite no rebanho. Quando a frequência média anual foi de 7 e 15\%, o maior foi ocasionado pelo descarte de leite de animais em tratamento, que foi de $\mathrm{R} \$ 68.474,00$ (42,7\%) e R $\$ 146.730,00$ (52,9\%), respectivamente. Esse fato foi devido ao aumento da quantidade de tratamentos curativos de casos clínicos no rebanho. Os percentuais de 7 e 15\% das frequências médias anuais são considerados acima do ideal, segundo SANTOS; FONSECA (2007) que é de $1 \%$. No entanto, vários pesquisadores têm relatado valores bem maiores, chegando a 63,7\% (DEGRAVES; FETROW, 1993).

O valor observado neste estudo, relacionado à redução na produção por vaca em lactação, ocasionada pela mastite subclínica, de $\mathrm{R} \$ 318,65$ (US\$ 141,50), foi inferior ao observado por CosTA et al. (1999), ao relatar que, no Brasil, somente as perdas com mastite subclínica podem chegar a US\$ 317,38 /vaca. Tais pesquisadores estudaram 7.644 glândulas mamárias de 2.208 vacas leiteiras das raças Holandesa, Jersey, Pardo Suíça e Mestiças, mantidas em confinamento total, parcial ou pasto. As perdas relacionadas à redução na produção foram estimadas pelo escore de quartos com California Mastitis Test positivo, com redução de 4,5 a 35,5\% . Esse percentual de redução na produção, ocasionado por mastite subclínica, foi superior aos valores deste estudo, que foram de, no máximo, $18 \%$ na redução da produção, quando se adotou CCST de 1.000.000 de células somáticas/mL. No entanto, neste estudo, para a maior CCST estudada, com estimativa de redução de $18 \%$, os valores observados com as perdas foram superiores (US\$ 384,24). SANTOS; FONSECA (2007) citaram que CCST de 1.500 .000 reduz 29\% na produção. Uma possível explicação para essa diferença é que, nesta pesquisa, foram considerados os extratos de perdas (250.000; 500.000; 750.000 e 1.000 .000 de células / $\mathrm{mL}$ de leite), e na pesquisa de Costa et al. (1999) os pesquisadores consideraram a média das 34 
propriedades acompanhadas e a mensuração foi por meio de escore de Califórnia Mastitis Test dos animais; e neste estudo foi adotado a CCST.

As perdas por redução na produção de leite tiveram altas representatividades, sendo responsáveis por até $43,8 \%$ do impacto econômico, em virtude do alto nível de mastite subclínica; também sofreram influência dos valores do litro de leite atribuídos. Os valores observados ainda estão abaixo do relato de Costa et al. (2005), que afirmaram que tais perdas podem chegar a $82 \%$.

A desvalorização de matrizes acometidas por mastite crônica, devido ao descarte involuntário, representou 12,3 a 3,2\% do impacto total, de acordo com a frequência de mastite clínica estudada. A desvalorização dos animais é um item que prejudica o pecuarista, uma vez que a cada animal descartado serão necessários investimentos para reposição. LOPEs et al. (2009) verificaram que a desvalorização das vacas descartadas involuntariamente é bastante acentuada, uma vez que as fêmeas que não estavam nesse grupo renderam uma receita de $\mathrm{R} \$ 2.680,00$; as fêmeas comercializadas devido ao descarte involuntário, dos quais os pesquisadores citam problemas mamários, resultou em receita de somente $\mathrm{R} \$ 882,00$ / vaca, o que representou $67,09 \%$ de desvalorização. Valores tão baixos se devem ao fato que esses animais são comercializados pelo valor pago por arroba da vaca, enquanto as vacas oriundas de descarte voluntário são animais eliminados de um rebanho e vendidos para outro, pois ainda possuem capacidade produtiva.

A receita bruta foi de $\mathrm{R} \$ 454.471,98 ; \mathrm{R} \$ 395.779,98$ e 317.523,98, o que correspondeu a soma dos valores apurados com a venda de leite $(98,5 ; 98,2$ e $97,8 \%)$ e animais (1,5; 1,8 e 2,2\%); para frequências médias anuais de mastite clínica de 1, 7 e 15\%, respectivamente. Como era de se esperar, a receita bruta proveniente do leite aumentou, à medida que houve redução da frequência média anual de casos clínicos. Tal fato ocorreu em virtude da maior quantidade de leite comercializado, o que está de acordo com Lopes et al. (2006b), ao constatarem que parte da renda foi devido à maior produção e parte à bonificação recebida pelas maiores produções. Neste trabalho, a bonificação foi de $R \$ 0,01 / \mathrm{kg}$ de leite comercializado quando a produção diária foi entre 1.001 a $3.000 \mathrm{~kg} /$ dia (100 vacas em lactação x $20 \mathrm{~kg} /$ dia, que resultou em $2.000 \mathrm{~kg}$ de leite/dia).

Quanto à venda de animais, não há menção na literatura de qual percentual seria o ideal para esses valores. No entanto, os valores aqui apresentados são pequenos quando comparadas aos obtidos por LOPES et al. (2008), que encontraram 7,55; 16,26 e $3,14 \%$ e Lopes et al. (2006a) (20,29; 7,29 e 9,70\% para pequenos, médios e grandes produtores). As diferenças nos percentuais podem ser ao fato de que neste estudo foi considerado somente o descarte involuntário por mastite, enquanto que nos outros estudos mencionados consideraram a venda de todos os animais, o que possibilita aumentar a receita. LOPES et al. (2009) encontraram percentuais de 15 a $20 \%$ da receita bruta sendo proveniente da venda de animais, o que também está bem acima dos resultados observados neste estudo.

Os percentuais de prevenção, em relação à receita bruta, foram estimados em 3,16; 3,63 e 4,52\%, enquanto que os referentes ao tratamento curativo 1,$06 ; 8,55$ e $22,84 \%$ para frequência média anual de $1 ; 7$ e $15 \%$, respectivamente.

As perdas totais apresentaram o maior impacto, em relação à receita bruta dos sistemas de produção, sendo de 11,79; 28,37 e 60,01\%, para frequência média anual de $1 ; 7$ e 15\%. Essas foram compostas por: morte de matrizes $(0,66 ; 0,76$ e $0,94 \%)$; desvalorização de matrizes $(1,97 ; 2,27$ e 2,82\%); descarte de leite de animais em tratamento $(2,15 ; 17,30$ e $46,21 \%)$; e redução na produção $(7,01 ; 8,04 ; 10,03 \%)$, para frequência média anual de $1 ; 7$ e $15 \%$, respectivamente. $\mathrm{O}$ impacto econômico total da mastite resultou em 16,02; 40,55 e 87,37\%, para os mesmos níveis estudados.

\section{CONCLUSÕES}

O aumento da frequência média anual de mastite clínica influenciou diretamente no impacto econômico da mastite. Oelevado impacto econômico evidencia a necessidade de monitoramento da mastite e adoção de medidas preventivas, buscando reduzir a incidência da doença de forma a diminuir os prejuízos ocasionados.

As despesas com tratamento preventivo representaram, no máximo, 19,7\% do impacto econômico, o que demonstra vantagens em investir nessa prática, pois ela irá contribuir significativamente para diminuição dos custos relacionados à mastite.

\section{AGRADECIMENTOS}

Os autores agradecem à FAPEMIG e ao $\mathrm{CNPq}$ pelo apoio na realização deste estudo.

\section{REFERÊNCIAS}

BAR, D.; TAUER, L.W.; BENNETT, G.; GONZALEZ, R. N.; HERTL, J. A.; SCHUKKEN, Y. H.; SCHULTE, H. F.; WELCOME, F. L.; GRÖHN, Y. T. The cost of generic clinical mastitis in dairy cows as estimated by using dynamic programming. Journal of Dairy Science, v.91, n.6, p.2205-2214, 2008. 
BUENO, V.F.F.; NICOLAU, E.S.; MESQUITA, A.J.; RIBEIRO, A.R.; SILVA, J.A.B.; COSTA, E.O.; COELHO, K.O.; NEVES, R.B.S. Mastite bovina clínica e subclínica, na região de Pirassununga, SP: frequências e redução na produção. Ciência Animal Brasileira, v.3, n.2, p.47-52, 2002.

COSTA, E.O.; RIBEIRO, A.R.; WATANABE, E.T.

Mastite sub-clínica: prejuízos causados e os custos de prevenção em propriedades leiteiras. Napgama, v.2, n.2, p.16-20, 1999.

COSTA, E.O.; GARINO JÚNIOR, F.; WATANABE, E.T. Proporção de ocorrência da mastite clínica em relação à subclínica correlacionada com os principais agentes etiológicos. Napgama, v.4, n.3, p.10-13, 2001.

COSTA, E.O.; MOTA, R.; SANTOS, F.G.B. Contagem de células somáticas de amostras de leite de glândulas mamárias de fêmeas bovinas em lactação infectadas por microrganismos dos gêneros Streptococcus, Staphylococcus e Corynebacterium. Napgama, v.8, n.2, p.3-7, 2005.

CULLOR, J.S. The control, treatment, and prevention of the various types of bovine mastitis. Veterinary Medicine, Berlin, v.88, p.571-579, 1993.

DEGRAVES, F.J.; FETROW, J. Economics of mastitis and mastitis control. Veterinary Clinics of North America: Food Animal Practice, v.9, n.3, p.421-434, 1993.

FONSECA, L.F.L.; SANTOS, M.V. Qualidade do leite e controle de mastite. São Paulo: Lemos, 2000. 175p.

HOBLET, K.H.; SCHNITKEY, G.D.; ARBOUG, D. Costs associated with selected preventive practices and with episodes of clinical mastitis in nine herds with low somatic cell counts. Journal of the American Veterinary Medical Association, v.199, n.2, p.190-196, 1991.

KIRK, J. H.; BARTLETT, P. C. Economic impact of mastits in Michigan Hostein dairy herss using a computerized records system. Agri-Pratice, Quebec, v.9, n.1, p.3-6, 1988.

LOPES, M.A.; LIMA, A.L.R.; CARVALHO, F. de M.; REIS, R.P.; SANTOS, I.C.; SARAIVA, F.H. Efeito do tipo de sistema de criação nos resultados econômicos de sistemas de produção de leite na região de Lavras (MG). Ciência e Agrotecnologia, v.28, n.5, p.1177-1189, 2004.

LOPES, M.A.; CARMO, E.A.; LIMA, A.L.R.; CARVALHO, F.M. Análise da rentabilidadede uma empresa com opção de comercialização de queijo ou leite. Arquivo Brasileiro de Medicina Veterinária e Zootecnia, v.58, n.4, p.642-647, 2006a.

LOPES, M.A.; LIMA, A.L.R.; CARVALHO, F. de M.; REIS, R.P.; SANTOS, I.C.; SARAIVA, F.H. Efeito da escala de produção nos resultados econômicos de sistemas de produção de leite na região de Lavras (MG): um estudo multicasos. Boletim da Indústria Animal, v.63, n.3, p.177-188. 2006b.

LOPES, M.A.; SANTOS, G.; COSTA, G.M.; LOPES, N.M. Desenvolvimento de um sistema computacional para avaliar o impacto econômico da mastite em rebanhos leiteiros. In: CONGRESSO BRASILEIRO DE AGROINFORMÁTICA, 6., 2007, São Pedro. Anais. São Pedro: SBIAgro, 2007. p.1-5.

LOPES, M.A.; CARDOSO, M.G.; CARVALHO, F.M.; LIMA, A.L.R.; DIAS, A.S.; CARMO, E.A. Resultados econômicos da atividade leiteira na região de Lavras (MG) nos anos 2004 e 2005: um estudo multicasos. Arquivo Brasileiro de Veterinária e Zootecnia, v.60, n.2, p.428-435, 2008.

LOPES, M.A.; CARDOSO, M.G.; DEMEU, F. A. Influência de diferentes índices zootécnicos na composição e evolução de rebanhos bovinos leiteiros. Ciência Animal Brasileira, v.10, n.2, p.446-453, 2009a.

MILLER, R.H.; PAAPE, M.J.; FULTON, L.A. The relationship of milk somatic cell count to milk yields for holstein heifers after first calving. Journal of Dairy Science, v.76, n.3, p.728-733, 1993.

NICKERSON, S.C.; OLIVER, S.P.; SMITH, K.L.; SORSILLO, L.M. Current concepts of bovine mastitis. 4.ed. Madison: National Mastitis Council, 1996. 64p.

OLIVEIRA, V.M.; CARNEIRO, A.V.; SILVA, M.R. benefícios de um programa de controle de mastite bovina em condições brasileiras de criação. In: CONGRESSO PANAMERICANO DE LEITE, 9., 2006, Juiz de Fora. Anais. Juiz de Fora: UFJF, 2006. 1 CD-ROM.

SANTOS, M.V.; FONSECA, L.F.L. Estratégias para controle de mastite e melhoria da qualidade do leite. São Paulo: Manole, 2007. 313p.

SILVA, L.A.F.; COELHO, K.O.; MACHADO, P.F.; SILVA, M.A.M.; MOURA, M.I.; BARBOSA, V.T.; GOULART, M.M.; GOULART, D.S. Causas de descarte de vacas da raça holandesa confinadas em uma população de 2.083 bovinos (2000-2003). Ciência Animal Brasileira, v.9, n.2, p.383-389, 2008.

VIANNI, M.C.E.; LÁZARO, N.S. Perfil de suscetibilidade a antimicrobianos em amostras de cocos Gram-positivos, catalase negativos, isolados de mastite subclínica bubalina. Pesquisa Veterinária Brasileira, v.23, n.2, p.47-51, 2003.

Recebido em 24/11/11

Aceito em 15/10/12 